\title{
The effects of emotional intelligence on counterproductive work behaviors
}

\author{
Seyed Morteza Emami*
}

Department of Industrial Engineering, Tarbiat Modares University, Tehran, Iran

\begin{tabular}{|c|c|}
\hline CHRON I C LE & ABSTRACT \\
\hline $\begin{array}{l}\text { Article history: } \\
\text { Received January } 28,2014 \\
\text { Received in revised format } \\
5 \text { May } 2014 \\
\text { Accepted } 4 \text { July } 2014 \\
\text { Available online } \\
\text { July } 5 \text { 2014 } \\
\text { Keywords: } \\
\text { Emotional intelligence } \\
\text { Counterproductive work behavior } \\
\text { Industrial Projects Management of }\end{array}$ & $\begin{array}{l}\text { This paper presents an empirical investigation to study the effects of emotional intelligence on } \\
\text { counterproductive work behavior. The study uses a questionnaire for measuring the effects of } \\
\text { emotional intelligence, which consists of four components including self-awareness, self- } \\
\text { control, self-motivation and empathy. In addition, the study uses another questionnaire to } \\
\text { measure the effects of counterproductive work behavior. The study has accomplished among } \\
\text { full time employees who work for Industrial Projects Management of Iran (IPMI), as a general } \\
\text { contractor, undertakes EPC projects in field of oil, gas and petrochemical industries in Iran. } \\
\text { Using structural equation modeling, the study has determined a negative and meaningful } \\
\text { relationship between various components of emotional intelligence and counterproductive work } \\
\text { behavior. }\end{array}$ \\
\hline
\end{tabular}

\section{Introduction}

Many people believe emotional intelligence (EQ) is more effective on the success of individuals as well as business organizations compared with Intelligence quotient (IQ). However, EQ may also influence negatively on work conditions. Jung and Yoon (2012) investigated the effects of emotional intelligence on counterproductive work behaviors (Kozako et al., 2013; Zhao et al., 2013) and organizational citizen behaviors among food and beverage employees in a deluxe hotel. They reported that as elements of emotional intelligence, others' emotion appraisal, use of emotion, and self-emotion appraisal substantially influenced counterproductive work behaviors, while self-emotion appraisal and use of emotion influenced organizational citizen behaviors. Besides, moderating effects were evident associated with job positions in the causal relationships among emotional intelligence, counterproductive work behaviors, and organizational citizen behaviors. Hanzaee and Mirvaisi (2013) performed a survey on the effect of emotional intelligence, organizational citizenship behaviors and job satisfaction on employees' performance in Iranian hotel industry.

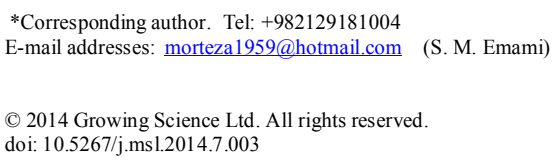


Saeidipour et al. (2012) reported that that emotional intelligence had a significant effect on organizational learning. Cretu and Burcas (2014) explored the relationship between emotional dissonance and a series of other certain indicators of counterproductive work behaviors specific to employees in the customer service field. They reported that emotional dissonance, self-efficacy and self-monitoring were significant predictors for employees' counterproductive behaviors at work. The study also identified a moderating impact of self-efficacy variable upon the relationship between emotional dissonance and counterproductive behaviors.

\section{The proposed study}

This paper presents an empirical investigation to study the effects of emotional intelligence on counterproductive work behavior. The study uses a questionnaire for measuring the effects of emotional intelligence developed by Salovey and Mayer (1989), which consists of four components including self-awareness, self-control, self-motivation and empathy. In addition, the study uses another questionnaire to measure the effects of counterproductive work behavior (Fox et al., 2001). The study has accomplished among full time employees who work for Industrial Projects Management of Iran (IPMI), as a general contractor (GC), undertakes EPC projects in field of oil, gas and petrochemical industries in Iran. The sample size of the study is calculated as follows,

$$
n=\frac{N \times z_{\alpha / 2}^{2} \times p \times q}{\varepsilon^{2} \times(N-1)+z_{\alpha / 2}^{2} \times p \times q},
$$

where $N$ is the population size, $p=1-q$ represents the yes/no categories, $z_{\alpha / 2}$ is CDF of normal distribution and finally $\varepsilon$ is the error term. Since we have $p=0.5, z_{\alpha / 2}=1.96$ and $N=260$, the number of sample size is calculated as $n=152$. Fig. 1 demonstrates the summary of personal characteristics of the participants.

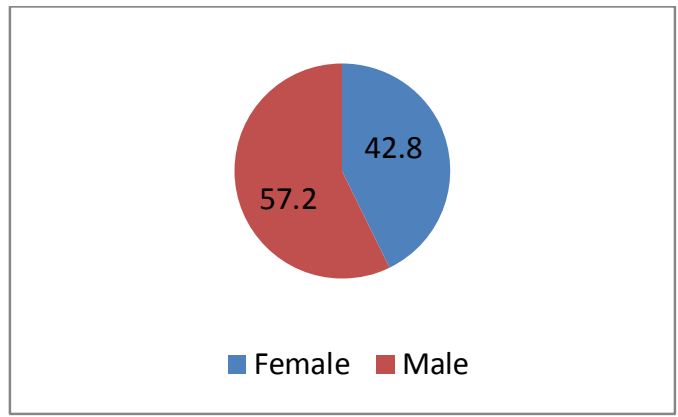

Gender

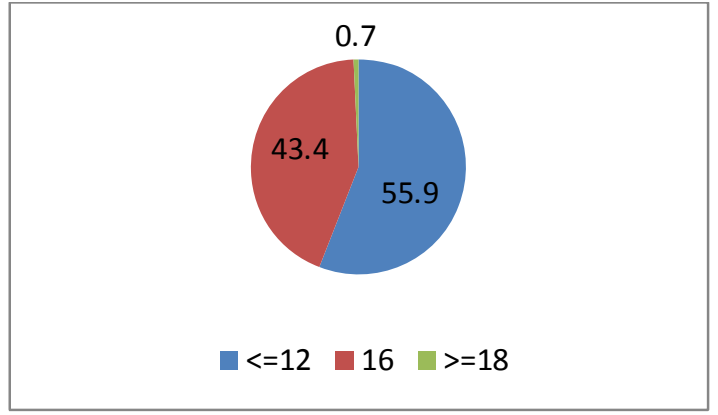

Years of education

Fig. 1. Personal characteristics of the participants

As we can observe from the results of Fig. 1, 43.4\% of the participants hold bachelor of sciences and more than half of the participants were male. Cronbach alphas for emotional intelligence and counterproductive work behaviors were calculated as 0.88 and 0.80 , respectively. These are well above the minimum acceptable levels of 0.70 and verify the overall questionnaire. The study uses structural equation modeling to verify the effects of four emotional components on counterproductive work behaviors as follows,

1. Empathy (EMP) negatively influences on counterproductive work behaviors (CWB).

2. Self-motivation (SM) negatively influences on counterproductive work behaviors.

3. Self-awareness (SA) negatively influences on counterproductive work behaviors.

4. Self-control (SC) negatively influences on counterproductive work behaviors. 
Table 1 summarizes some basic statistics associated with the implementation of structural equation modeling.

\section{Table 1}

The summary of some basic statistics on SEM implementation

\begin{tabular}{cccccccccc}
\hline Index & P_value & $\chi^{2} /$ df & RMSEA & CFI & NFI & NNFI & GFI & IFI & RMR \\
\hline Acceptable Value & $<0.05$ & $<5$ & $<0.1$ & $>0.9$ & $>0.9$ & $>0.9$ & $>0.9$ & $>0.9$ & $<0.05$ \\
Value & 0.00 & 1.47 & 0.08 & 0.99 & 0.736 & 0.99 & 0.738 & 0.99 & 0.112 \\
\hline
\end{tabular}

As we can observe from the results of Table 1, most statistics are within acceptable limits.

\section{The results}

The implementation of structural equation modeling has been accomplished using LISREL software package. Fig. 2 demonstrates the results of our findings.

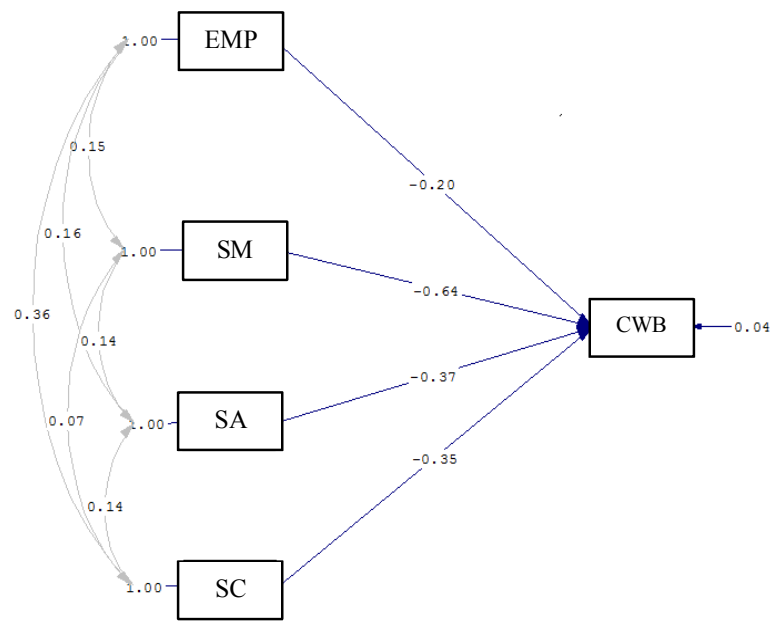

Standard coefficients

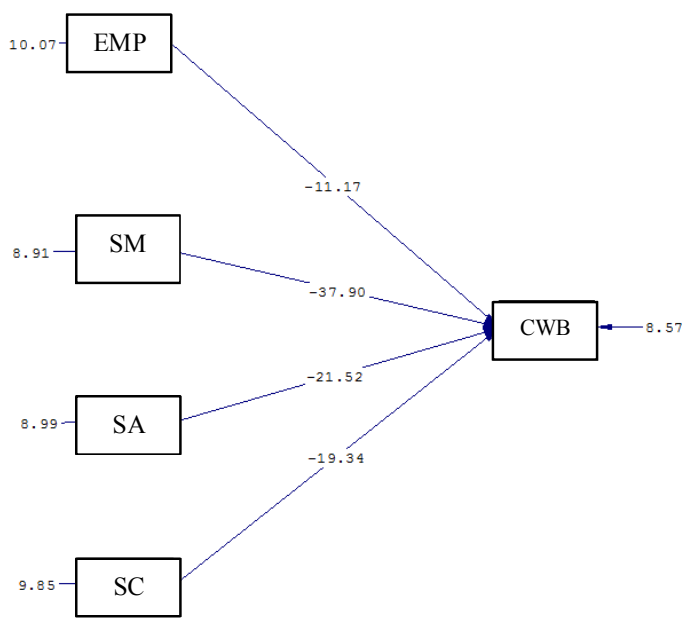

t-value coefficients

Fig. 2. The results of the implementation of structural equation modeling

As we can observe from the results of Fig. 2, all components of the survey are statistically significant $(\alpha=5 \%)$ and we can confirm four hypotheses of the survey. Table 2 shows details of our results.

\section{Table 2}

The summary of testing different hypotheses

\begin{tabular}{lccc}
\hline Hypothesis & $\beta$ & t-value & Result \\
\hline Empathy (EMP) negatively influences on counterproductive work behaviors. & -0.2 & -11.17 & Confirmed \\
Self-motivation (SM) negatively influences on counterproductive work behaviors. & -0.64 & -37.90 & Confirmed \\
Self-awareness (SA) negatively influences on counterproductive work behaviors. & -0.37 & -21.52 & Confirmed \\
Self-control (SC) negatively influences on counterproductive work behaviors. & -0.35 & -19.34 & Confirmed \\
\hline
\end{tabular}

\section{Conclusion}

In this paper, we have presented an empirical investigation to study the effects of emotional intelligence on counterproductive work behaviors in one of Iranian contractors. The study has implemented structural equation modeling to verify different hypotheses of the survey. The results have indicated that self-motivation has the most negative impact on counterproductive work behavior $(\beta=-0.64)$ followed by self-awareness $(\beta=-0.37)$, self-control $(\beta=-0.35)$ and empathy $(\beta=-0.2)$. 


\section{Acknowledgement}

The authors would like to thank the anonymous referees for constructive comments on earlier version of this paper.

\section{References}

Cretu, R. Z., \& Burcas, S. (2014). Self Efficacy: A moderator of the relation between emotional dissonance and counterproductive work behavior. Procedia-Social and Behavioral Sciences, 127, 892-896.

Fox, S., Spector, P. E., \& Miles, D. (2001). Counterproductive work behavior (CWB) in response to job stressors and organizational justice: Some mediator and moderator tests for autonomy and emotions. Journal of vocational behavior,59(3), 291-309.

Hanzaee, K., \& Mirvaisi, M. (2013). A survey on impact of emotional intelligence, organizational citizenship behaviors and job satisfaction on employees' performance in Iranian hotel industry. Management Science Letters, 3(5), 1395-1402.

Jung, H. S., \& Yoon, H. H. (2012). The effects of emotional intelligence on counterproductive work behaviors and organizational citizen behaviors among food and beverage employees in a deluxe hotel. International Journal of Hospitality Management, 31(2), 369-378.

Kozako, I. N. A. M. F., Safin, S. Z., \& Rahim, A. R. A. (2013). The relationship of big five personality traits on counterproductive work behaviour among hotel employees: An exploratory study. Procedia Economics and Finance, 7, 181-187.

Saeidipour, B., Akbari, P., \& Fashi, M. (2012). Study the effect of emotional intelligence on organizational learning staff, Case study: Jihad Agriculture Organization of Isfahan. Management Science Letters, 2(7), 2501-2510.

Salovey, P., \& Mayer, J. D. (1989). Emotional intelligence. Imagination, cognition and personality, 9(3), 185-211.

Zhao, H., Peng, Z., \& Sheard, G. (2013). Workplace ostracism and hospitality employees' counterproductive work behaviors: The joint moderating effects of proactive personality and political skill. International Journal of Hospitality Management, 33, 219-227. 